\title{
Synergistic promoting effects of pentoxifylline and simvastatin on the apoptosis of triple-negative MDA-MB-231 breast cancer cells
}

\author{
YESSICA CRISTINA CASTELLANOS-ESPARZA ${ }^{1,2^{*}}$, SHUANG WU ${ }^{1,3^{*}}$, LIMIN HUANG ${ }^{1,5}$, CATHERINE BUQUET ${ }^{4}$, \\ RONG SHEN $^{1}$, BERENICE SANCHEZ-GONZALEZ ${ }^{2}$, ETHEL AWILDA GARCÍA LATORRE ${ }^{2}$, \\ OLIVIER BOYER ${ }^{4}$, REMI VARIN ${ }^{4}$, LUIS ANTONIO JIMÉNEZ-ZAMUDIO ${ }^{2}$, ANNE JANIN $^{1}$, \\ JEAN-PIERRE VANNIER ${ }^{4}, \mathrm{HONG} \mathrm{LI}^{4}$ and $\mathrm{HE} \mathrm{LU}^{1}$ \\ ${ }^{1}$ National Institute of Health and Medical Research, Medical Research Unit S-1165/Paris Diderot University, \\ University Institute of Hematology, Saint-Louis Hospital, 75010 Paris, France; ${ }^{2}$ Immunochemistry Laboratory I, \\ Immunology Department, National School of Biological Sciences, National Polytechnic Institute, \\ Mexico City 11340, Mexico; ${ }^{3}$ West China Second University Hospital, Sichuan University, \\ Chengdu, Sichuan 610065, P.R. China; ${ }^{4}$ National Institute of Health and Medical Research, \\ Unit 1234/Rouen University, Faculty of Medicine and Pharmacy, 76183 Rouen, France
}

Received April 27, 2017; Accepted November 14, 2017

DOI: $10.3892 /$ ijo.2018.4272

\begin{abstract}
Pentoxifylline (PTX), a xanthine family molecule and simvastatin (SIM), an anti-hypercholesterolemic agent, have recently been considered as sensitizers to chemotherapy and radiotherapy. The present in vitro study evaluated their antitumor synergistic effects on MDA-MB-231 breast cancer cells characterized by the triple-negative phenotype (TNP). The anti-proliferative effects of these two agents were evaluated by MTT and clonogenic assays. Cell cycle progression was examined using propidium iodide staining. Apoptosis was investigated by Annexin $\mathrm{V}$ labeling, and by examining caspase 3 activity and DNA fragmentation. Autophagic vesicles and reactive oxygen species (ROS) levels were monitored by flow cytometry. Western blot analysis was performed to evaluate molecular targets. Our results revealed that when used alone, PTX and SIM exerted antitumor effects. Nevertheless, used in combination, the inhibition of cell proliferation was
\end{abstract}

Correspondence to: Dr He Lu, INSERM UMR-S 1165, IUH, 1 Avenue Claude Vellefaux, Hôpital Saint-Louis, 75010 Paris, France E-mail: he.lu@inserm.fr

Dr Hong Li, INSERM U1234/University, Faculty of Medicine and Pharmacy, 22 Boulevard Gambetta, Rouen 76183 Cedex, France

E-mail: li.lu-hong@univ-rouen.fr

Present address: ${ }^{5}$ Department of Oncology, Guizhou Provincial People's Hospital, 83 Zhongshan East Road, Guiyang, Guizhou 550002, P.R. China

*Contributed equally

Key words: pentoxifylline, simvastatin, apoptosis, autophagy, breast cancer synergistically superior ( $80 \%$ vs $42 \%$ ) than that observed following treatment with each agent alone after $48 \mathrm{~h}$. PTX alone $(0.5 \mathrm{mM})$ induced both apoptosis $(25 \%)$ and autophagy $(25 \%)$; however, when used in combination with SIM $(0.5 \mu \mathrm{M})$, the balance between these processes was disrupted and the cells underwent apoptosis $(>65 \%)$ as opposed to autophagy $(<13 \%)$. This imbalance was associated with an increase in ERK1/2 and AKT activation, but not with an increase in mTOR phosphorylation, and with the suppression of the NF- $\kappa \mathrm{B}$ pathway. In addition, in the cells treated with both agents, almost $78 \%$ of the cells were arrested at the G0/G1 phase and lost their colony-forming ability $(38 \pm 5 \%)$ compared to the cells treated with PTX alone $(115 \pm 5 \%)$. On the whole, these results suggest that the induction of autophagy may be a protective mechanism preventing MDA-MB-231 cancer cell death. The combined use of PTX and SIM may drive dormant autophagic cancer cells to undergo apoptosis and thus this may be a novel treatment strategy for breast cancer characterized by the TNP.

\section{Introduction}

Breast cancer is associated with the highest incidence and mortality rates of malignancies affecting women worldwide and the World Health Organization (WHO) estimates that the incidence of breast cancer will increase in the next 10 years (1). The triple-negative phenotype (TNP) pertaining to the absence or very low expression of estrogen, progesterone and epidermal growth factor receptors, is one of the most aggressive breast cancer subtypes that correlates with a poor prognosis (2). These characteristics combined with limited therapeutic choices frequently lead to chemoresistance and metastasis $(3,4)$. Therefore, the development of novel therapeutic strategies is urgently required.

Simvastatin (SIM), a lipophilic statin widely used as an anti-cholesterolemic drug, has shown potential for use in the suppression of the proliferation and metastasis of colon, 
prostate, melanoma, lung, lymphoma, liver and breast cancer cells (5-10). In addition, the protective effects of SIM have been reported in a prospective Danish study where women prescribed with SIM exhibited reduced breast cancer risk for several years (11). This agent acts by inhibiting the 3-hydroxy3-methylglutaryl-coenzyme A (HMG-CoA) reductase in the mevalonate pathway, blocking the formation of intermediary products in the biosynthesis of cholesterol, such as geranylgeranyl and farnesyl pyrophosphate, and affecting the prenylation of small GTPases, such as Rho, Ras and others (12). SIM deregulates isoprenylation compounds, resulting in a direct effect against the activation of cell proliferation, adhesion and survival signaling cascades (13). Some data suggest that SIM can reverse acquired resistance to cetuximab, bortezomib or doxorubicin, and is capable of suppressing cancer stem-like populations in human breast cancer $(6,14-16)$.

Pentoxifylline (PTX), a methylxanthine derivate, is well known for its effects as a sensitizer to chemo-radiotherapy (17). It has been used in clinical practice as a hemorheologic agent for more than 35 years, due to its abilities of improving oxygenation, lower platelet aggregation and thrombus formation (18). PTX has also been reported to have biological activities, such as those of a phosphodiesterase inhibitor, inflammatory cytokine regulator, immunomodulator, antioxidant and antifibrotic agent (19). Oncological studies have indicated that PTX in combination with thiotepa, cisplatin, melphalan, doxorubicin, vincristine or the proteasome inhibitor, MG132, exerts anti-proliferative effects probably by stimulating pro-apoptotic signals (20-22). Recent studies have also demonstrated its capacity to modify the expression profiles of matrix metalloproteinase (MMP)-2 and MMP-9, adhesion molecules, and chemokine receptors in melanoma cells and MDA-MB-231 breast cancer cells $(23,24)$.

Recently, an increasing number of novel target molecules and novel drugs have made readily available in clinical practice or are currently undergoing clinical trials or are under development. However, their therapeutic effects seem less than satisfactory. On the other hand, rational drug use and the best combination regimen would also lead to better anticancer therapy. Thus, the aims of this study were to determine an effective combination treatment, in an aim to help the clinician to establish an ideal protocol for improving the management of breast cancer characterized by TNP. The drugs SIM and PTX have been proven to exert antitumor effects individually; however, to date, at least to the best of our knowledge, their combined effects on breast cancer cells with the TNP have not yet been examined. Therefore, this study was carried out to evaluate the hypothesis that the concomitant administration of both these compounds may strengthen their anticancer effects.

\section{Materials and methods}

Cell culture and treatment. The MDA-MB-231 human breast cancer cells (HTB-26, ATCC ${ }^{\circledR}$ ) were cultured at $37^{\circ} \mathrm{C}$ with $5 \%$ of $\mathrm{CO}_{2}$ in RPMI-1640 medium (Eurobio, Les Ulis, France) containing $10 \% \mathrm{FBS}, 1 \%$ glutamine and $0.1 \%$ antibiotics (penicillin/streptomycin). The cells were treated alone or in combination with SIM (Sigma) dissolved in DMSO and PTX (Sigma) in PBS at the indicated concentrations. Cells treated with DMSO $(<0.1 \%)$ were used as controls.
Cell viability and clonogenic assay. The sensitivity to cytotoxic drugs was evaluated by colorimetric MTT (Alfa Aesar, Ward Hill, MA, USA) assay. Following overnight seeding into 96-well culture plates, the cells were treated with $0-50 \mu \mathrm{M}$ of SIM or 0-50 mM of PTX for 24-48 h. Subsequently, $10 \mu \mathrm{l}$ of MTT reagent were added to each well followed by incubation of $3 \mathrm{~h}$. Absorbance was measured on an ELISA reader (BioTek Instruments, Inc., Winooski, VT, USA) at a $550 \mathrm{~nm}$ wavelength. Cell viability percentages were calculated taking into account the control as $100 \%$. The half maximal inhibitory concentration $\left(\mathrm{IC}_{50}\right.$ ) value was estimated in each case employing GraphPad Prism v6 statistical software. Subtoxic concentrations $(0.5 \mathrm{mM}$ for PTX and $0.5 \mu \mathrm{M}$ for SIM) were selected for combination studies and their cytotoxicity was evaluated by MTT assay. The combination index values were calculated based on the Chou-Talalay median-effect equation $(25,26)$ permitting the mathematical prediction of the response nature as synergy $<1$, additive $=1$ and antagonism $>1$ using fractional effects of $\mathrm{IC}_{25}, \mathrm{IC}_{50}, \mathrm{IC}_{75}$ and $\mathrm{IC}_{90}$.

SIM at $0.5 \mu \mathrm{M}$ and PTX at $0.5 \mathrm{mM}$ were also used to treat the cells in the presence or absence of the autophagy blocker, 3-methyladenine $1 \mathrm{mM}$ (Sigma-Aldrich, St. Louis, MO, USA) for $24 \mathrm{~h}$. The survival rates of these cells were then analyzed by MTT assay.

Colony formation assay was performed to evaluate the long-term effects on cell recovery and the ability of the cells to proliferate and form new colonies. The colony formation assay was performed with washed drug-treated cells (after 24 and $48 \mathrm{~h}$ of treatment with SIM at $0.5 \mu \mathrm{M}$ and PTX at $0.5 \mathrm{mM}$ ) in drug-free medium. The cells were then re-seeded in 6 well-plates (200 cells/well) and incubated in drug-free medium for a further 14 days. Subsequently, the cells were fixed with $4 \%$ paraformaldehyde and stained with crystal violet $0.2 \%$ (Sigma-Aldrich); colonies consisting of at least 50 cells were counted under an inverse microscope (ZEISS-Axiovert 135, Zeiss, Oberkochen, Germany). Data are expressed in terms of survival fraction (SF) which corresponds to the quotient between sample plating efficiency (PE) and control PE (27). In the figures, images are representative of colonies formed by surviving cells after 14 days and bar charts (\%) represent the colony numbers versus the initial seeded cell number.

Cell cycle analysis. The effects of the treatments on cell cycle distribution were examined by propidium iodide (PI) staining detected by flow cytometry. Following treatment for 24-48 h, the cells were trypsinized and collected by centrifugation, fixed in $70 \%$ of cold ethanol, washed with PBS and were then diluted in $100 \mu \mathrm{l}$ of mixture solution containing PI $(1 \mathrm{mg} / \mathrm{ml})$ and RNase $(50 \mu \mathrm{g} / \mathrm{ml})$, and incubated in the dark for $30 \mathrm{~min}$. Acquisition samples were made using a FACSCalibur ${ }^{\mathrm{TM}}$ cytometer (BD Biosciences, San Jose, CA, USA) in FL-2 channel and data were analyzed using FlowJo V.x.0.7 software (Tree Star Inc., Ashland, OR, USA). Pre-G0 was defined as the signals at the left of the G0/G1 pick, essentially known as the cell debris in the flow cytometer.

Annexin V-FITC labeling. To accomplish cytotoxic knowledge, quantitative and descriptive tests were carried out to reveal the nature and degree of cell death caused by the treatment agents. Apoptosis was quantified following the specifications 
of the Annexin V-FITC PI detection kit (4A Biotech Co., Beijing, China). Briefly, the cells were seeded in 6 well-plates following by treatments for 12,24 and $36 \mathrm{~h}$. The cells were then collected by trypsinization, washed and incubated for $15 \mathrm{~min}$ with $100 \mu 1$ of staining buffer. Acquisition and analysis were carried out on an FACSCalibur ${ }^{\mathrm{TM}}$ cytometer (BD Biosciences) using FL-1 and FL-3 channels.

Caspase 3 activity assay. The activity of the apoptotic caspase 3 enzyme was measured using Ac-DEVD-AMC substrate (Enzo Life Sciences, Farmingdale, NY, USA), a fluorogenic molecule that contains the same amino acid sequence site of the PARP cleavage, and it is weakly fluorescent, but following proteolytic cleavage by caspase 3 it becomes highly fluorescent. After 24-48 $\mathrm{h}$ of incubation with the drugs, the cells were lysed in $200 \mu \mathrm{l}$ of ice-cold lysis buffer (without protease inhibitors) and $25 \mu \mathrm{l}$ of homogenized cell lysate was transferred to a black multi-well plate format containing $175 \mu 1$ of reaction buffer per well and $10 \mu \mathrm{l}$ of substrate were added to each well. The fluorescence intensity was measured within $2 \mathrm{~h}$ using a plate reader with an excitation and emission maximum of 360 and $440 \mathrm{~nm}$, respectively. Percentage of activity was normalized vs. the control without treatment.

Cell death detection and DNA fragmentation examined by ELISA. The cell death detection ELISA ${ }^{\text {PLUS }}$ (Roche, Indianapolis, IN, USA) kit was used to quantify the DNA fragments induced by apoptosis processes and present inside cytoplasm or apoptotic bodies, as the kit quantifies the histone-complexed DNA fragments (mono- and oligonucleosomes) out of the cytoplasm of cells after the induction of apoptosis. Briefly, the cells were treated for $24-48 \mathrm{~h}$ and were then lysed for $30 \mathrm{~min}$ at room temperature and centrifuged at $200 \mathrm{x}$ g for $10 \mathrm{~min}$. ELISA was carried out using $20 \mu \mathrm{l}$ of supernatants and $80 \mu \mathrm{l}$ of immunoreagent placed into a well of a strepvidin-coated microplate. The samples were incubated for $2 \mathrm{~h}$ at room temperature, washed and re-incubated for 15 min with ABTS substrate. Stop reaction solution was added and the density optical values were obtained using $405 \mathrm{~nm}$ of wavelength on ELISA reader (BioTek Instruments, Inc.). The enrichment of mono- and oligonucleosomes in the cytoplasm were calculated and normalized vs. the control.

Autophagy analysis. The percentage of programmed cell death type II or autophagy was determined using the Cyto-ID ${ }^{\circledR}$ autophagy detection kit (Enzo Life Sciences) which labels specifically autophagosomes vacuoles or autophagolysosomes. The cells were processed identically as for apoptosis detection, but stained for $30 \mathrm{~min}$ with Cyto-ID reagent diluted in $500 \mu \mathrm{l}$ of medium without phenol red enriched with 5\% FBS. Data were obtained using the same resources as those for cell cycle assay using the FL-1 channel. Other autophagy markers (LC3A/B) were also determined by western blot analysis using anti LC3A/B antibody $\left(\mathrm{Abcam}^{\circledR}\right)$ as described below.

Detection of intracellular ROS production. The general redox-stage in the treated cells was detected using dichlorodihydrofluorescein diacetate (DCFH-DA) dye. This probe is based on the formation and intracellular accumulation of fluorescent products (green) resulting from H2DCF-DA (non-fluorescent) oxidation by reactive oxygen species (ROS). After $24 \mathrm{~h}$ of cell seeding, the medium was replaced with phenol red-free RPMI containing $10 \mu \mathrm{M}$ of H2DCF-DA and the respective drug concentrations followed by incubation for $1 \mathrm{~h}$ in standard culture conditions at $37^{\circ} \mathrm{C}$. Subsequently, following trypsinization, the cellular suspension was immediately analyzed by flow cytometry using the FL-1 channel.

Cytokine array. Cytokine expression profiles were evaluated following the instructions of the manufacturer of the RayBio ${ }^{\circledR}$ Human Cytokine Antibody Array (RayBiotech, Norcross, GA, USA). Briefly, supernatants of the cells exposed to treatments for $24 \mathrm{~h}$ were recovered by centrifugation $(3,500 \mathrm{x} \mathrm{g})$. Each experimental membrane (provided with the kit) was then blocked prior to incubation with the samples overnight at $4^{\circ} \mathrm{C}$. After washes, the membranes were incubated for $1 \mathrm{~h}$ with biotin-coupled primary antibodies (provided with the kit by the manufacturer), washed and covered with HRP-conjugated streptavidin for $2 \mathrm{~h}$. The detection was made by exposing the membranes to chemiluminescence in the Gene Snap Syngene v7.09.17 (Ingenius Bioimaging) instrument and signal intensities were quantified by densitometry.

Western blot analysis. After $24 \mathrm{~h}$ of treatment, the cells were lysed using RIPA solution (containing protease inhibitor) under 10 pulses of sonication with $60 \%$ amplitude. The lysate was allowed to stand for $30 \mathrm{~min}$ and proteins were collected by centrifugation at $3,500 \mathrm{x}$ g. All preparations were processed on ice or $4^{\circ} \mathrm{C}$. Protein concentrations were determined by Bradford method and western blot analysis was carried out according to conventional methods. The primary antibodies against p38k (9212), phosphor-p38k (9211), mTOR (2983), phosphor-mTOR (5536), p65 (8242), phosphor-p65 (3033), $\operatorname{IKB} \alpha$ (4814), phosphor-IKB $\alpha$ (2859), IKK $\alpha$ (11930), IKK $\beta$ (8943), phosphor-IKK $\alpha \beta$ (2697), ERK1/2 (9102), phosphor-ERK1/2 (9106) were purchased from Cell Signaling Technology (Danvers, MA, USA). Antibodies against AKT1/2 (sc-1619), phosphor-AKT1/2 (sc-7985-R), PI3K (sc-1637) were from Santa Cruz Biotechnology (Santa Cruz, CA, USA). $\beta$-actin antibody was from Sigma-Aldrich Co. (A2228) and LC3A/B (ab128025) antibody was from Abcam (Cambridge, MA, USA).

Statistical analysis. Data are expressed as the means \pm standard deviation of 2 or 3 independent experiments carried out in triplicate. Differences between groups were determined by one or two statistical methods: ANOVA followed by post hoc correction using GraphPad Prism 6 software. A value of $\mathrm{P}<0.05$ was considered to indicate a statistically significant difference.

\section{Results}

Synergistic inhibitory effects of PTX and SIM on cell growth. Both apoptosis and autophagy are dynamic processes which occur prior to cell death. Therefore, it was necessary to examine the effects at different time points for the different tests. We usually selected the time points of $12-24 \mathrm{~h}$ for intracellular signaling analysis and 36 or $48 \mathrm{~h}$ for the observation of the effects on cell viability or cell death. When used 
A
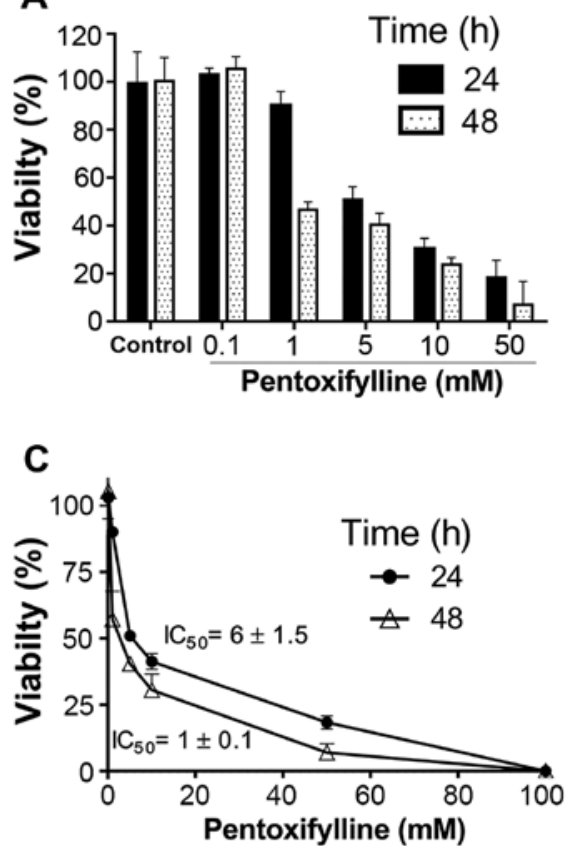

E

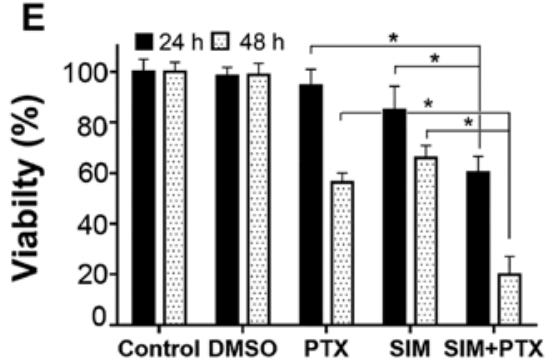

B

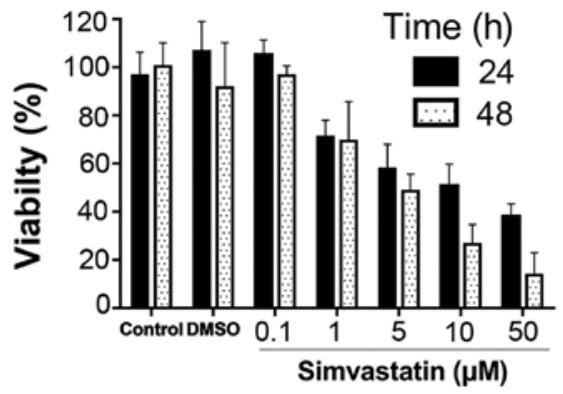

D

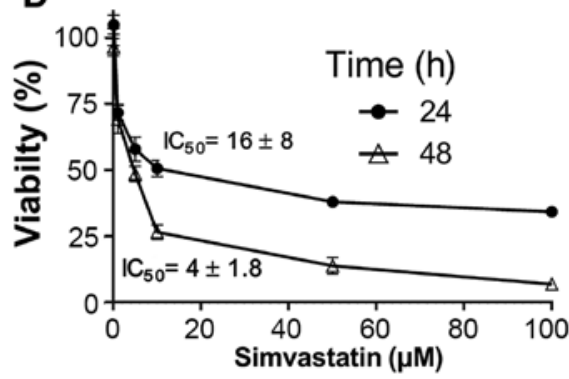

F

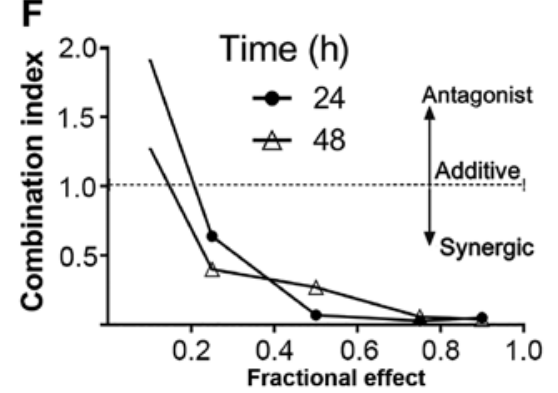

Figure 1. Viability of MDA-MB-231 cells after 24-48 h of treatment with PTX and SIM. Cytotoxic response to different regimes of drugs was evaluated by MTT assay with cultured MDA-MB-231 cells at 24 or $48 \mathrm{~h}$. (A and B) Dose-dependent effects of the drugs alone, PTX and SIM. (C and D) Inhibitory concentration $50\left(\mathrm{IC}_{50}\right)$ values for PTX- and SIM-treated cells. (E) Cell chemosensitivity to SIM $(0.5 \mu \mathrm{M}), \mathrm{PTX}(0.5 \mathrm{mM})$ or their combination. (F) Combination index values calculated based on the Chou-Talalay median-effect equation, indicating the response nature of drugs combination as synergy $<1$, additive $=1$ and antagonism $>1 .{ }^{*} \mathrm{P}<0.01$ vs. control and/or to individual treatments. Filled circles represent the calculated data of the experiments after $24 \mathrm{~h}$ of cell incubation with both drugs and open triangles represent the calculated data of the experiments after $48 \mathrm{~h}$ of cell incubation with the two drugs.

alone, both SIM and PTX inhibited cell proliferation in a dose-dependent manner (Fig. $1 \mathrm{~A}$ and $\mathrm{B}$ ). The $\mathrm{IC}_{50}$ values were $16 \pm 8$ and $4 \pm 1.8 \mu \mathrm{M}$ for SIM, and were $6 \pm 1.5$ and $1 \pm 0.1 \mathrm{mM}$ for PTX after 24 and $48 \mathrm{~h}$ of treatment, respectively (Fig. 1C and D). When the cells were treated with $0.5 \mathrm{mM}$ of PTX in combination with $0.5 \mu \mathrm{M}$ of SIM, as shown in Fig. 1E, cell proliferation was inhibited by $>38 \%$ and $80 \%$ at 24 and $48 \mathrm{~h}$, as compared to the single drug-treated controls (15-42\%). This indicated that the inhibitory effect was approximately doubled as compared to treatment with SIM and PTX alone. Mathematical data validation suggested a strong synergistic inhibitory effect on cell growth by the combined use of the two drugs for 24 and $48 \mathrm{~h}$ (Fig. 1F). In order to make data analysis easier, the cells were treated with fixed doses of $0.5 \mathrm{mM}$ PTX and $0.5 \mu \mathrm{M}$ SIM in the following experiments.

Cell apoptosis was analyzed in both early and late stages using different assays. In Annexin V labeling detection, the positive cell number in the mono-treated groups increased to approximately $25 \%$ at 24 and $36 \mathrm{~h}$, whereas combined treatment increased the apoptosis to approximately $65 \%$, and approximately $>2$-fold as compared to treatment with SIM or
PTX alone (Fig. 2A). Consistently, increased levels of DNA fragmentation were observed in the SIM + PTX-treated cells at $24 \mathrm{~h}$ (Fig. 2B). In accordance with the Annexin $\mathrm{V}$ and DNA fragmentation results, caspase 3 activity was elevated at $24 \mathrm{~h}$ in all groups and the highest levels were observed in the combination group (Fig. 2C). Thus PTX and SIM induced apoptosis and the combined use of both agents further amplified cell apoptosis.

PTX and SIM combination treatment reduces cell autophagy. Autophagy was analyzed with the cells after treatment. As shown in Fig. 2D, 0.5 mM PTX induced approximately 20-28\% of cell autophagy, whereas $0.5 \mu \mathrm{M}$ SIM treatment led to a much lower induction (only approximately 3\%). However, when PTX was used in combination with SIM, the autophagic cell level was significantly diminished to $13 \%$ after $36 \mathrm{~h}$ of treatment. This was confirmed by western blot analysis following treatment with anti-LC3A/B antibody, a marker of autophagy (Fig. 2E and F), showing a decrease in the LC3-II/LC3-I ratio. When the cells were treated with SIM for $24 \mathrm{~h}$, a very low percentage of autophagic cells was observed (Fig. 2D); however, a relatively 
A

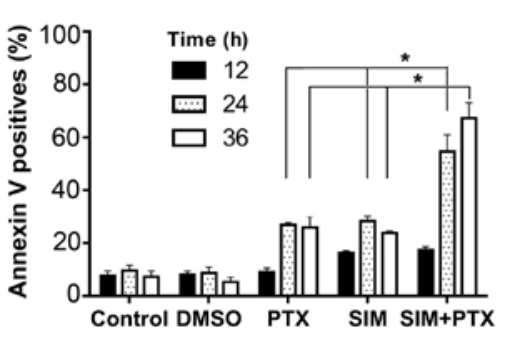

C

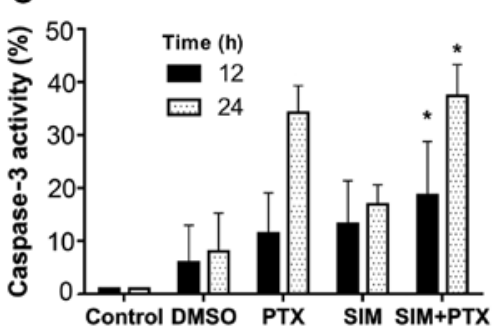

E
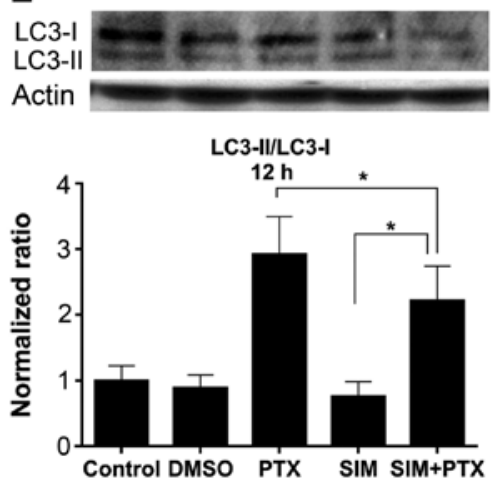

B

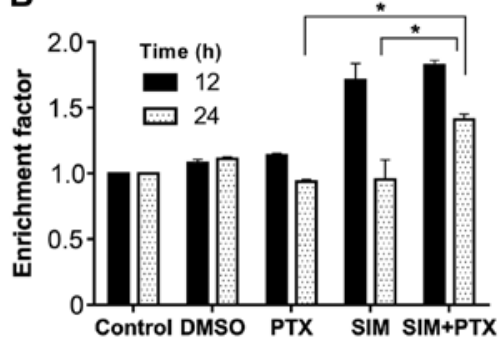

D

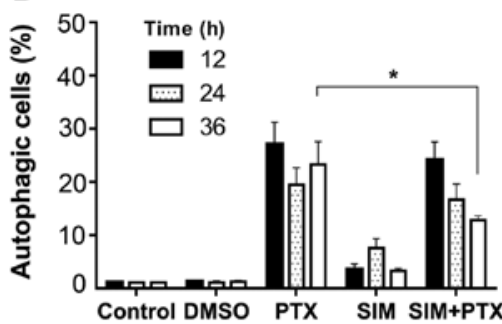

$\mathbf{F}$

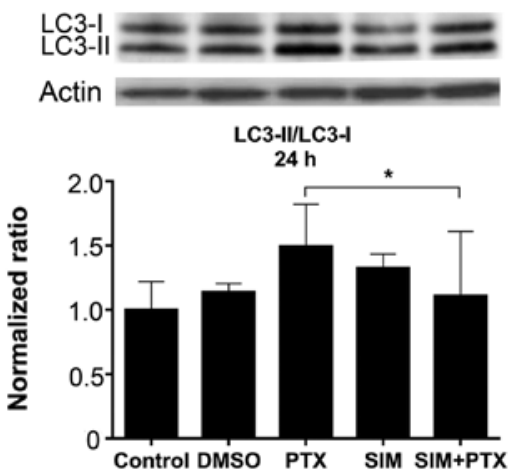

Figure 2. Co-administration of SIM and PTX increases apoptosis and decreases autophagy levels in MDA-MB-231 cells. The cells were treated with SIM $(0.5 \mu \mathrm{M}), \mathrm{PTX}(0.5 \mathrm{mM})$ or their combination for the indicated periods of time. (A) Apoptotic cells positive for Annexin V labeling. (B) DNA fragmentation levels were evaluated by the Cell Death Detection ELISA ${ }^{\text {PLUS }}$ kit and the results correlated with enrichment factors. (C) Caspase 3 activity. (D) Autophagolysosome cell level positive to Cyto-ID. (E and F) Western blot analysis for the autophagy marker, light chain 3 (LC3A/B) at 24 and 48 h, respectively. ${ }^{*}<0.05$ vs. control and/or to individual treatments.

high LC3-II/LC3-ratio was observed (Fig. 2F). It was suggested that the process of autophagy was also terminated after the formation of LC3-associated autophagosomes. The possible mechanisms may be the inhibition of autophagosome fusion with lysosomes or other unidentified causes.

Cell cycle blockage at the G0/G1 phase is enhanced by combination treatment. Following centrifugation, the supernatants containing very small dead cell fragments were washed out and the cell pellets were used for cell cycle analysis. The 3 treatment groups showed visible blockage at the G0/ G1 phase after $24 \mathrm{~h}$ of treatment, especially the combination group (Fig. 3A). After $48 \mathrm{~h}$ of treatment, cell death occurred, indicating an important appearance of the pre-G0 phase which was composed of cell debris in the SIM and SIM+PTX groups $(\mathrm{P}<0.01$ vs. PTX group), with a significant decrease in the number of cells in the $S$ and G2M phases. The cells in the PTX group had accumulated in the G0/G1 phase instead of the pre-G0 phase after death (Fig. 3B).

Autophagy blockage enhances cell mortality following combination treatment. To examine whether autophagy is suppressed by SIM, the autophagy inhibitor, 3-MA, was used to treat the PTX- and SIM-treated cells. As shown in Fig. 3C, cell viability was reduced by approximately $10 \%$ in the PTX-treated cells following the addition of 3-MA; however, the cells in the SIM-treated group were not affected. When 3-MA was added to the PTX + SIM-treated cells, no further inhibition was observed. The absence of the additional inhibition by 3-MA in the PTX + SIM group indicated that PTX-induced autophagy was efficiently suppressed by SIM. Therefore, autophagy seemed to promote cancer resistance and acted as a pro-survival factor.

Combination treatment suppresses long-term cell survival. Cell clonogenic assay was performed to further establish the association between cell growth inhibition and cell survival. The cells were cultured with the drugs for either 24 or $48 \mathrm{~h}$, washed and then seeded into plates. After 15 days following these treatments, as shown in Fig. 3D, the colony formation ability of the cells was examined and the colony numbers were approximately $115-120 \%$ for the PTX group, $62-75 \%$ for the SIM group and $38-32 \%$ for the combination group at 24 and $48 \mathrm{~h}$, respectively. These results indicated that the marked 

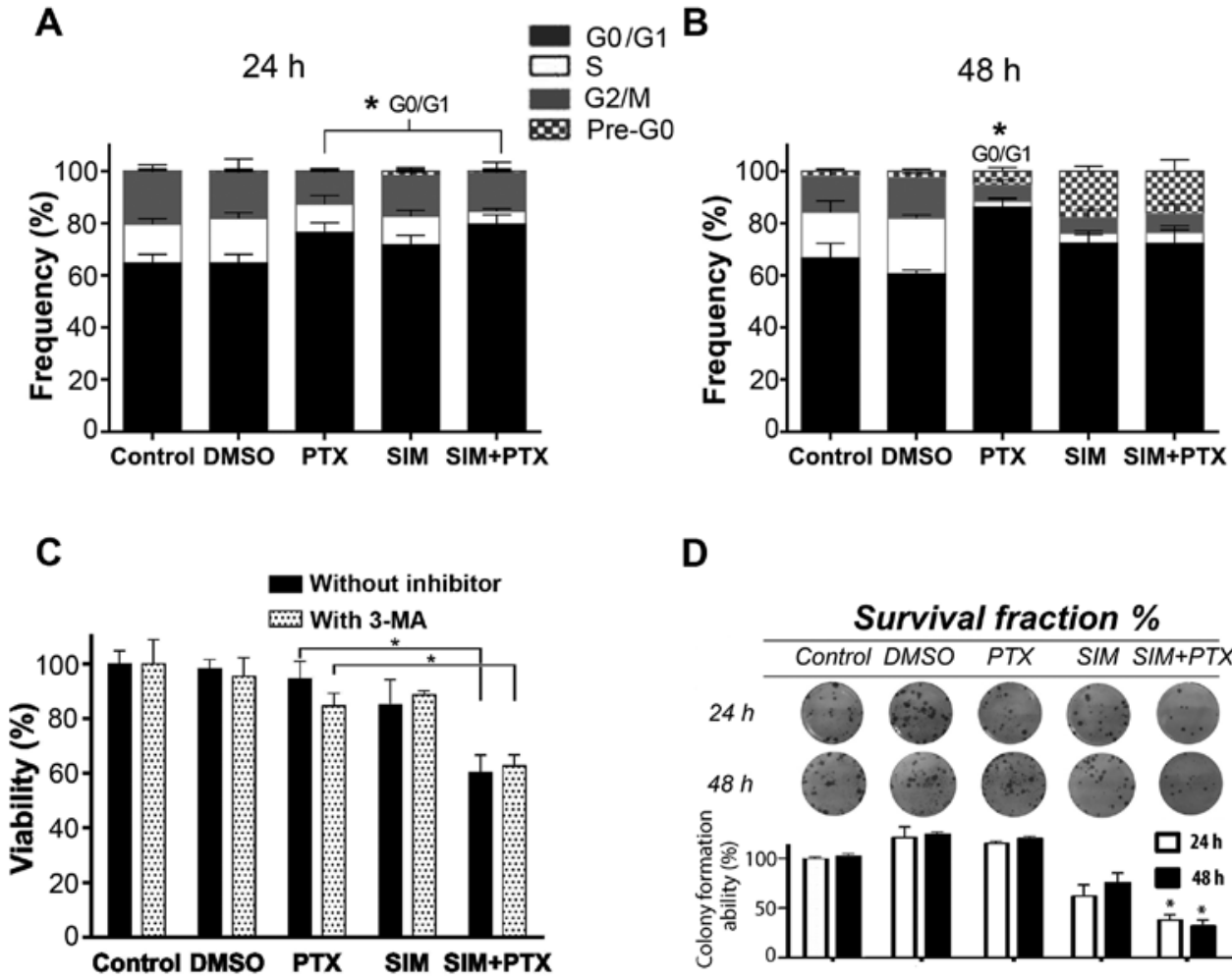

D

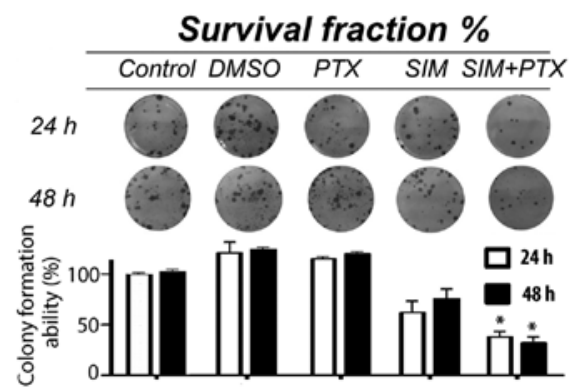

Figure 3. Effects of treatment with SIM, PTX or their combination on cell cycle phases and survival. The MDA-MB-231 cells were treated for 24 or $48 \mathrm{~h}$ and then analyzed. (A and B) Cell cycle distribution is presented as a percentage of G0/G1, S, G2/M and pre-G0 stages after 24-48 h. (C) SIM and PTX were used to treat the cells in the presence or absence of the autophagy blocker, 3-MA $(1 \mathrm{mM})$, for $24 \mathrm{~h}$. The survival rates of these cells were analyzed. "P<0.05 vs. control and/or to individual treatments. (D) The colony formation assay was performed with washed drug-treated cells (after 24 and $48 \mathrm{~h}$ of treatment) in drug-free medium. The images are representative of colonies formed by surviving cells after 14 days and the bar chart (\%) represents the colony numbers vs. the initially seeded cell number. ${ }^{*} \mathrm{P}<0.05$ vs. other groups.

A

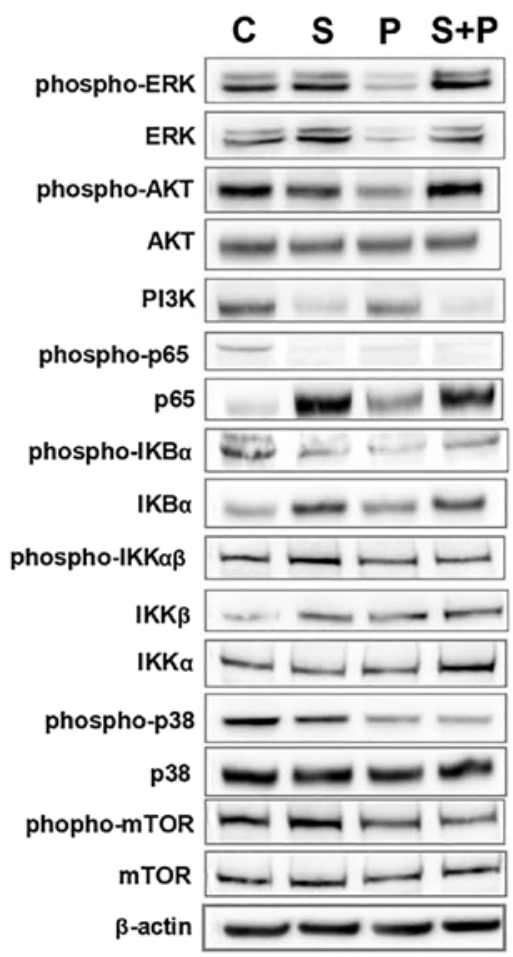

B
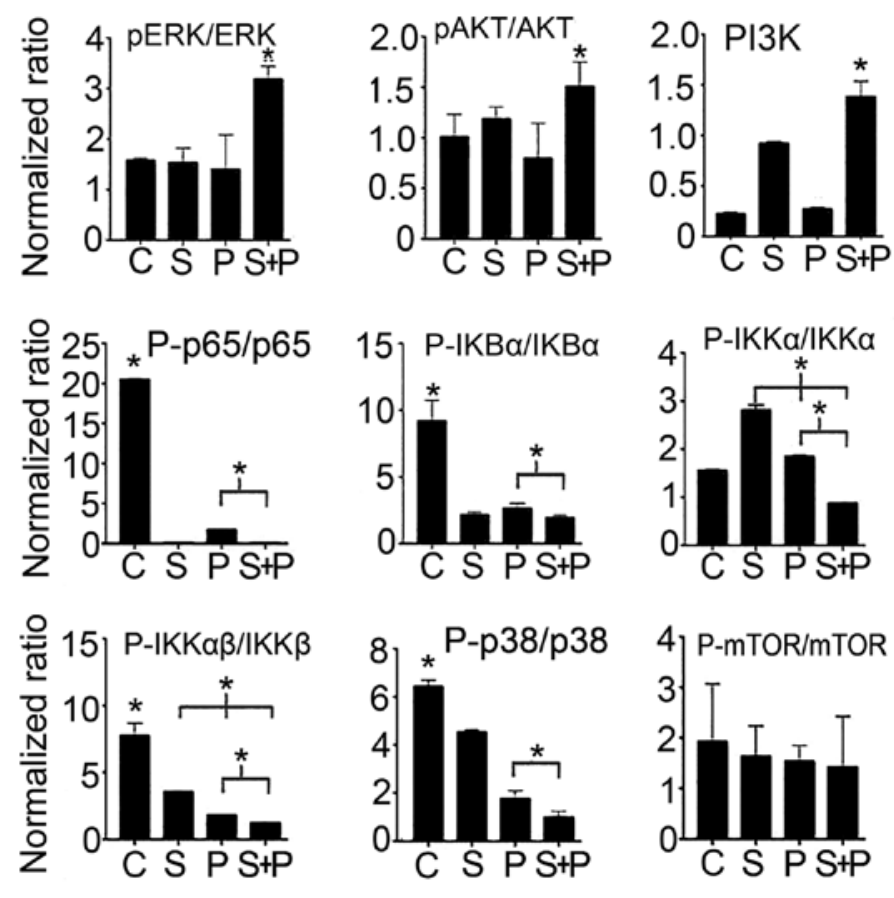

Figure 4. Relative expression of signaling pathway proteins and their activation levels after $24 \mathrm{~h}$ of treatment. The cells were collected after $24 \mathrm{~h}$ of drug treatment and used for western blot analysis. (A) Representative images of band intensities in western blot films. (B) Normalized ratio of phosphorylated/ total protein. " $\mathrm{P}<0.05$ vs. control and/or to individual treatments. The bars are labeled as follows: C, control; D, DMSO; S, simvastatin; $\mathrm{P}$, pentoxifylline; $\mathrm{S}+\mathrm{P}$, simvastatin + pentoxifylline. 

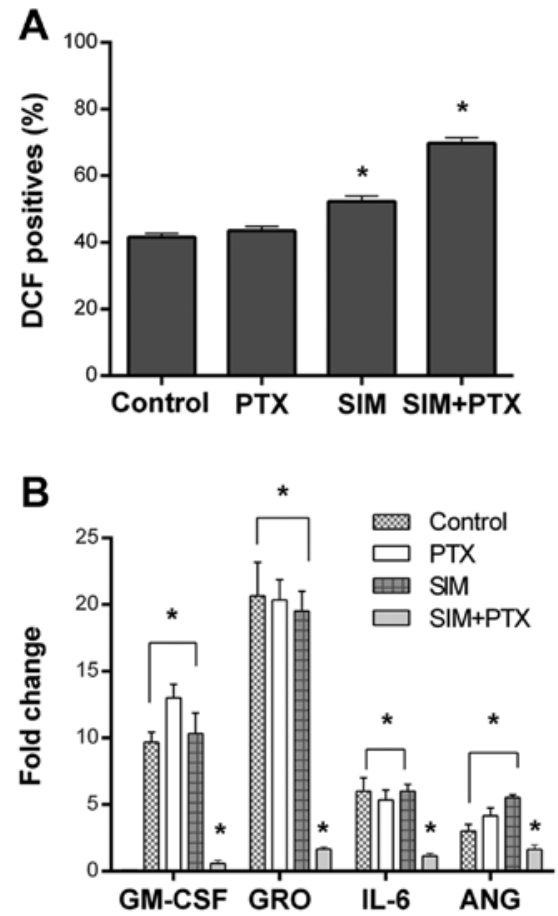

Figure 5. ROS levels and cytokine array analysis. (A) The cells were incubated with the drugs for $1 \mathrm{~h}$ and intracellular ROS levels were measured using a flow cytometer. The results revealed the percentage of DCF-positive cells corresponding to the cell stress level. (B) Culture media from the cell culture after $24 \mathrm{~h}$ drug treatment were collected, centrifuged and tested for cytokine array analysis. The results are presented as normalized fold change compared to the control. ${ }^{*} \mathrm{P}<0.05$ vs. control and/or to individual treatments.

PTX pro-autophagic effect was associated with an unusual cell survival and resumed growth ability. This observation was in favor of the hypothesis that the addition of SIM to PTX counterbalanced the PTX pro-autophagic effect.

Cell signaling is deregulated by combined treatment with PTX and SIM. In order to investigate the conceivable molecular mechanisms implicated in the combined effects of PTX and SIM, different cell signaling molecules were probed. As shown in Fig. 4, the results of western blot analysis revealed that ERK and AKT were significantly activated following combination treatment as compared to the untreated control cells and to the cells treated with PTX or SIM alone (increase of $>50 \%$ by examining the p-ERK/ERK ratio), although neither PI3K nor mTOR expression was elevated. Furthermore, the NF- $\kappa \mathrm{B}$ signaling pathway in the cells treated with both agents was downregulated, as evidenced by the decreased $\mathrm{p} 65$ (p-p65/p-65) and IKK (p-IKK $\alpha / \operatorname{IKK} \alpha$ and p-IKK $\beta / \operatorname{IKK} \beta$ ) activation levels compared to the cells treated with PTX alone. The NF-kB signaling pathway is known to rescue cells from apoptosis; its downregulation in the cells treated with both agents may decrease chances of survival. Another signaling molecule p38 also showed a significant downregulation in the cells treated with both agents compared to the cells treated with PTX or SIM alone. However, the levels of reactive oxygen species (ROS) were upregulated in the SIM + PTX group when compared with the mono treatments (Fig. 5A).

Cytokine array assays revealed a significant downregulation of GM-CSF, GRO, IL-6 and angiotensin when the cells were treated with SIM + PTX. These cytokines are known to play key roles in local inflammation (Fig. 5B) (28).

\section{Discussion}

In this study, to the best of our knowledge, we report for the first time an alternative approach with which to enhance the sensitivity of the triple-negative breast cancer cell line, MDA-MB-231, involving the co-administration of SIM and PTX. The results revealed that the cell growth and cell cycle were inhibited by either SIM or PTX mono-treatments; however, the combination of both drugs synergistically augmented these effects. Our results revealed that PTX induced mostly G0/G1 cell cycle arrest as shown by flow cytometry, as also previously reported (22). We further observed (Fig. 3B) that in combination with SIM, PTX decreased the number of cells in the $\mathrm{G} 0 / \mathrm{G} 1$ phase and the cells began to shrink into the pre-G0 phase with cell fragmentation after $48 \mathrm{~h}$ of treatment. This explained the accelerated cell death at $24 \mathrm{~h}$ to $48 \mathrm{~h}$, as observed in Fig. 1E. We also observed a shift in the balance between apoptosis and autophagy at the $24 \mathrm{~h}$ time point. SIM induced mainly cell apoptosis, while PTX induced both cell autophagy and apoptosis. When the two drugs were used in combination, the autophagic rates were reduced, while the apoptotic levels were inversely increased. These results strongly support the existence of a well-regulated balance between apoptosis and autophagy. Therefore, our study revealed most likely an interesting pharmaceutical property of SIM, indicating that it is capable of breaking the balance, altering cell destination and inducing cell death.

The experiments with the autophagy inhibitor, 3-MA, revealed that the addition of 3-MA affected the survival of PTX-treated cells, but not that of SIM or PTX + SIM-treated cells. This indicated an efficient blockage of autophagy by SIM. Autophagy is considered a cell self-adaptation mechanism against environment-associated stress and starvation (29). It is known to be closely connected to apoptosis within cells since both the stimulation and inhibition of autophagy have been reported to promote tumor cell apoptosis (30-32). In this study, we performed clonogenic experiments to determine whether PTX-induced autophagy can attenuate or counterbalance apoptosis as a pro-survival factor in MDA-MB-231 cells. The results revealed that the PTX-treated cells re-grew very well and rapidly formed new colonies after withdrawing PTX, demonstrating that autophagic tumor cells were able to escape from the death following treatment by PTX. Therefore, these results are consistent with the notion that autophagy activation plays a role in tumor cell resistance to drugs. This phenomenon is believed to be relevant to clinical cancer resistance, particularly due to the growth of residue dormant cancer cells following chemotherapy $(32,33)$.

An attempt was made to elucidate the plausible molecular mechanisms of cell signaling pathways of combination treatment. In the combination-treated cells, we observed the activation of the ERK $1 / 2$ and AKT pathways, but not the pro-autophagic mTOR pathway as compared to the mono treatments, as the p-ERK1/2 and p-Akt ratio was increased, but not mTOR expression was not. To date, the role of ERK in the induction of apoptosis is still under debate (34). ERK inhibition has been reported to be necessary for apoptosis in 
MDA-MB-231 and other tumor cells (17,32,35-38). However, others have shown that ERK activation is required for the induction of apoptosis (39-43). The reason for the discrepancy of these opposing observations remains unclear, and both could be true due to their complex connections to different downstream signal molecules in different cells. Our study suggested the involvement of ERK/AKT activation using combined treatment. We further demonstrated that the ERK-downstream targets, ROS and p38, also reacted in this manner (ROS was upregulated but p-p38 was downregulated).

We further investigated ERK-downstream targets by examining the NF- $\kappa B$ signaling pathway, since NF- $\kappa \mathrm{B}$ is known to prevent cell apoptosis. Indeed, in the combined treatment group, NF- $\mathrm{kB}$ signaling was found to be inhibited, as shown by the low or suppressed levels of the activation of p65 and IKK proteins. Since the NF- $\kappa$ B signaling pathway rescues cells from apoptosis, its absent response to ROS stress and further downregulation in the combination-treated cells may be a mechanism with which to decrease chances of cell survival.

In fact, the two drugs may affect tumor growth by other mechanisms, such as cell-cell dialogues, local inflammatory reaction and tumor angiogenesis $(44,45)$. Our results of cytokine array supported such an assumption, as the combination treatment downregulated the secretion of several inflammatory cytokines, such as IL-6, GRO, GM-SCF and angiotensin by the tumor cells. The reduced secretion of these cytokines can be expected to lessen tumor-induced local inflammation. As local inflammation is known to promote tumor angiogenesis and metastasis, therefore, an additional benefit of PTX + SIM treatment could be expected from the diminution of inflammation and angiogenesis within tumors.

Taken together, our results demonstrated a potential benefit of combined therapy of PTX and SIM, which transforms autophagic cancer cells into apoptotic cells, more efficiently prevents tumor cell growth, and more efficiently suppresses triple-negative breast cancer cells. At present, although many mechanisms involved in this effect still remain to be investigated, we hope that our results may be useful for further studies and beneficial to clinical cancer therapy.

\section{Acknowledgements}

Y.C. Castellanos-Esparza was financially supported by a grant from the National Polytechnic Institute (IPN) and the National Council for Science and Technology (CONACyT) from Mexico. S. Wu was financially supported by the Chinese Scholarship Council. We are grateful to Mrs. Elizabeth Le Grand, Dr T. Simon, Dr Alexander Petit and Dr Isabel Dubus for their kind assistance.

\section{References}

1. Jemal A, Bray F, Center MM, Ferlay J, Ward E and Forman D: Global cancer statistics. CA Cancer J Clin 61: 69-90, 2011.

2. Chacón RD and Costanzo MV: Triple-negative breast cancer Breast Cancer Res 12 (Suppl) 2: S3, 2010.

3. Reddy KB: Triple-negative breast cancers: An updated review on treatment options. Curr Oncol 18: e173-e179, 2011.

4. Dawson SJ, Rueda OM, Aparicio S and Caldas C: A new genome-driven integrated classification of breast cancer and its implications. EMBO J 32: 617-628, 2013.
5. Relja B, Meder F, Wilhelm K, Henrich D, Marzi I and Lehnert M: Simvastatin inhibits cell growth and induces apoptosis and G0/G1 cell cycle arrest in hepatic cancer cells. Int J Mol Med 26: 735-741, 2010.

6. Lee J, Lee I, Han B, Park JO, Jang J, Park C and Kang WK: Effect of simvastatin on cetuximab resistance in human colorectal cancer with KRAS mutations. J Natl Cancer Inst 103: 674-688, 2011.

7. Hoque A, Chen $\mathrm{H}$ and $\mathrm{Xu} \mathrm{XC}$ : Statin induces apoptosis and cell growth arrest in prostate cancer cells. Cancer Epidemiol Biomarkers Prev 17: 88-94, 2008.

8. Favero GM, F Otuki M, Oliveira KA, Bohatch MS Jr, Borelli P, Barros FE, Maria DA, Fernandes D and Bydlowski SP: Simvastatin impairs murine melanoma growth. Lipids Health Dis 9: 142, 2010

9. Chan KK, Oza AM and Siu LL: The statins as anticancer agents. Clin Cancer Res 9: 10-19, 2003.

10. Qi XF, Zheng L, Lee KJ, Kim DH, Kim CS, Cai DQ, Wu Z, Qin JW, Yu YH and Kim SK: HMG-CoA reductase inhibitors induce apoptosis of lymphoma cells by promoting ROS generation and regulating Akt, Erk and p38 signals via suppression of mevalonate pathway. Cell Death Dis 4: e518, 2013.

11. Ahern TP, Pedersen L, Tarp M, Cronin-Fenton DP, Garne JP, Silliman RA, Sørensen HT and Lash TL: Statin prescriptions and breast cancer recurrence risk: A Danish nationwide prospective cohort study. J Natl Cancer Inst 103: 1461-1468, 2011.

12. Graaf MR, Richel DJ, van Noorden CJ and Guchelaar HJ: Effects of statins and farnesyltransferase inhibitors on the development and progression of cancer. Cancer Treat Rev 30: 609-641, 2004.

13. Rohilla A, Rohilla S, Kumar A, Khan MU and Deep A: Pleiotropic effects of statins: A boulevard to cardioprotection. Arab J Chem 9: S21-S27, 2016.

14. Gopalan A, Yu W, Sanders BG and Kline K: Eliminating drug resistant breast cancer stem-like cells with combination of simvastatin and gamma-tocotrienol. Cancer Lett 328: 285-296, 2013.

15. Fuchs D, Berges C, Opelz G, Daniel V and Naujokat C: HMG-CoA reductase inhibitor simvastatin overcomes bortezomib-induced apoptosis resistance by disrupting a geranylgeranyl pyrophosphate-dependent survival pathway. Biochem Biophys Res Commun 374: 309-314, 2008.

16. Sadeghi-Aliabadi H, Minaiyan M and Dabestan A: Cytotoxic evaluation of doxorubicin in combination with simvastatin against human cancer cells. Res Pharm Sci 5: 127-133, 2010.

17. Barancik M, Bohacova V, Gibalova L, Sedlak J, Sulova Z and Breier A: Potentiation of anticancer drugs: Effects of pentoxifylline on neoplastic cells. Int J Mol Sci 13: 369-382, 2012.

18. Słoczyńska K, Kózka M, Pękala E, Marchewka A and Marona H: In vitro effect of pentoxifylline and lisofylline on deformability and aggregation of red blood cells from healthy subjects and patients with chronic venous disease. Acta Biochim Pol 60: 129-135, 2013.

19. Goel PN and Gude RP: Delineating the anti-metastatic potential of pentoxifylline in combination with liposomal doxorubicin against breast cancer cells. Biomed Pharmacother 68: 191-200, 2014.

20. Bravo-Cuellar A, Hernández-Flores G, Lerma-Díaz JM, Domínguez-Rodríguez JR, Jave-Suárez LF, De Célis-Carrillo R, Aguilar-Lemarroy A, Gómez-Lomeli P and Ortiz-Lazareno PC: Pentoxifylline and the proteasome inhibitor MG132 induce apoptosis in human leukemia U937 cells through a decrease in the expression of Bcl-2 and Bcl-XL and phosphorylation of $\mathrm{p} 65$. J Biomed Sci 20: 13, 2013.

21. Fan S, Smith ML, Rivet DJ II, Duba D, Zhan Q, Kohn KW, Fornace AJ Jr and O'Connor PM: Disruption of p53 function sensitizes breast cancer MCF-7 cells to cisplatin and pentoxifylline. Cancer Res 55: 1649-1654, 1995.

22. Goel PN and Gude RP: Unravelling the antimetastatic potential of pentoxifylline, a methylxanthine derivative in human MDA-MB-231 breast cancer cells. Mol Cell Biochem 358: 141-151, 2011.

23. Kamran MZ and Gude RP: Preclinical evaluation of the antimetastatic efficacy of Pentoxifylline on A375 human melanoma cell line. Biomed Pharmacother 66: 617-626, 2012.

24. Goel PN and Gude RP: Pentoxifylline regulates the cellular adhesion and its allied receptors to extracellular matrix components in breast cancer cells. Biomed Pharmacother 68: 93-99, 2014.

25. Chou TC: Drug combination studies and their synergy quantification using the Chou-Talalay methodCancer Res 70: 440-446, 2010. 
26. Bhat UG, Pandit B and Gartel AL: ARC synergizes with ABT-737 to induce apoptosis in human cancer cells. Mol Cancer Ther 9: $1688-1696,2010$

27. Franken NA, Rodermond HM, Stap J, Haveman J and van Bree C: Clonogenic assay of cells in vitro. Nat Protoc 1: 2315-2319, 2006

28. Brasier AR: The nuclear factor-kappaB-interleukin-6 signalling pathway mediating vascular inflammation. Cardiovasc Res 86: 211-218, 2010.

29. Viry E, Paggetti J, Baginska J, Mgrditchian T, Berchem G, Moussay E and Janji B: Autophagy: An adaptive metabolic response to stress shaping the antitumor immunity. Biochem Pharmacol 92: 31-42, 2014.

30. Wang Y, Liu J, Qiu Y, Jin M, Chen X, Fan G, Wang R and Kong D: ZSTK474, a specific class I phosphatidylinositol 3-kinase inhibitor, induces G1 arrest and autophagy in human breast cancer MCF-7 cells. Oncotarget 7: 19897-19909, 2016

31. Giuliano S, Cormerais Y, Dufies M, Grépin R, Colosetti P, Belaid A, Parola J, Martin A, Lacas-Gervais S, Mazure NM, et al: Resistance to sunitinib in renal clear cell carcinoma results from sequestration in lysosomes and inhibition of the autophagic flux. Autophagy 11: 1891-1904, 2015.

32. Chu PM, Chen LH, Chen MT, Ma HI, Su TL, Hsieh PC, Chien CS, Jiang BH, Chen YC, Lin YH, et al: Targeting autophagy enhances BO-1051-induced apoptosis in human malignant glioma cells Cancer Chemother Pharmacol 69: 621-633, 2012.

33. Tucci M, Stucci S, Savonarola A, Resta L, Cives M, Rossi R and Silvestris F: An imbalance between Beclin-1 and p62 expression promotes the proliferation of myeloma cells through autophagy regulation. Exp Hematol 42: 897-908 e891, 2014

34. Cagnol S and Chambard JC: ERK and cell death: Mechanisms of ERK-induced cell death - apoptosis, autophagy and senescence. FEBS J 277: 2-21, 2010.

35. Sharma K, Ishaq M, Sharma G, Khan MA, Dutta RK and Majumdar S: Pentoxifylline triggers autophagy via ER stress response that interferes with Pentoxifylline induced apoptosis in human melanoma cells. Biochem Pharmacol 103: 17-28, 2016.

36. Wang T, Seah S, Loh X, Chan CW, Hartman M, Goh BC and Lee SC: Simvastatin-induced breast cancer cell death and deactivation of PI3K/Akt and MAPK/ERK signalling are reversed by metabolic products of the mevalonate pathway. Oncotarget 7 : 2532-2544, 2016.
37. Palanivel K, Kanimozhi V, Kadalmani B and Akbarsha MA Verrucarin A induces apoptosis through ROS-mediated EGFR/ MAPK/Akt signaling pathways in MDA-MB-231 breast cancer cells. J Cell Biochem 115: 2022-2032, 2014.

38. Zhang S, He Y, Tong Q, Chen Q, Wu X and Huang W: Deltonin induces apoptosis in MDA-MB-231 human breast cancer cells via reactive oxygen species-mediated mitochondrial dysfunction and ERK/AKT signaling pathways. Mol Med Rep 7: 1038-1044, 2013.

39. Wang X, Martindale JL and Holbrook NJ: Requirement for ERK activation in cisplatin-induced apoptosis. J Biol Chem 275: 39435-39443, 2000.

40. Pathania AS, Kumar S, Guru SK, Bhushan S, Sharma PR Aithagani SK, Singh PP, Vishwakarma RA, Kumar A and Malik F: The synthetic tryptanthrin analogue suppresses STAT3 signaling and induces caspase dependent apoptosis via ERK up regulation in human leukemia HL-60 cells. PLoS One 9: e110411, 2014.

41. Singh S, Upadhyay AK, Ajay AK and Bhat MK: p53 regulates ERK activation in carboplatin induced apoptosis in cervical carcinoma: A novel target of p53 in apoptosis. FEBS Lett 581: 289-295, 2007.

42. Pettersson F, Couture MC, Hanna N and Miller WH: Enhanced retinoid-induced apoptosis of MDA-MB-231 breast cancer cells by PKC inhibitors involves activation of ERK. Oncogene 23: 7053-7066, 2004.

43. Bacus SS, Gudkov AV, Lowe M, Lyass L, Yung Y, Komarov AP, Keyomarsi K, Yarden Y and Seger R: Taxol-induced apoptosis depends on MAP kinase pathways (ERK and p38) and is independent of p53. Oncogene 20: 147-155, 2001.

44. Landskron G, De la Fuente M, Thuwajit P, Thuwajit $C$ and Hermoso MA: Chronic inflammation and cytokines in the tumor microenvironment. J Immunol Res 2014: 149185, 2014.

45. Wang M, Zhao J, Zhang L, Wei F, Lian Y, Wu Y, Gong Z, Zhang S, Zhou J, Cao K, et al: Role of tumor microenvironment in tumorigenesis. J Cancer 8: 761-773, 2017. 